Original article

\title{
Compilation of a herbal medicine formulary for herbal substances in Malta and its usefulness amongst healthcare professionals
}

\author{
Maria Spiteri $^{\mathrm{a}, *}$, Everaldo Attard ${ }^{\mathrm{b}}$, Anthony Serracino-Inglott ${ }^{\mathrm{a}}$, Lilian M. Azzopardi ${ }^{\mathrm{a}}$ \\ ${ }^{a}$ Department of Pharmacy, Faculty of Medicine and Surgery, University of Malta, Msida, Malta \\ ${ }^{\mathrm{b}}$ Division of Rural Sciences and Food Systems, Institute of Earth Systems, University of Malta, Msida, Malta
}

\section{A R T I C L E I N F O}

\section{Article history:}

Received 11 August 2012

Accepted 10 January 2013

Available online 7 March 2013

\section{Keywords:}

Formulary

Healthcare

Herbal medicine

Pharmacist

Usefulness

\begin{abstract}
A B S T R A C T
Context: Today, the use of herbal medicine for primary healthcare has increased considerably. Since local pharmacists graduate with little knowledge on herbal medicine, the majority are ill-equipped to provide pharmaceutical advice.

Aims: To develop and evaluate a herbal medicine formulary to aid healthcare professionals (HCPs) in the prescribing, dispensing and counselling responsibilities.

Settings and Design: Community pharmacies.

Methods and Material: Monographs on all herbal substances available locally were compiled into a formulary. The formulary was then distributed to all, 216, local pharmacies. Subsequently, a questionnaire was distributed to 55 pharmacists and 10 general practitioners (GPs).

Statistical analysis used: Descriptive statistical analysis.

Results: A total of 177 herbal monographs have been compiled and 612 herbal products listed. Thirty HCPs participated in the questionnaire. The formulary was found to be useful by all participants with 19 claiming to use it frequently and 7 quite frequently. Participants $(n=30)$ agree that the information contained within the formulary was found to be useful (26), the formulary helped them learn which HMPs are present in the local market (29), the formulary is user friendly (27), information included is upto-date and well referenced (29) and that there is the need for a formulary of this kind in Malta (28). Conclusions: The formulary was found to be a useful tool for HCPs leading to high quality, evidence-based prescribing together with enhanced monitoring and improved patient care.

Copyright (c) 2013, InPharm Association, Published by Reed Elsevier India Pvt. Ltd. All rights reserved.
\end{abstract}

\section{Introduction}

Herbal medicine is one of the oldest forms of healthcare known to man. ${ }^{1}$ It has a very long history, going back to the beginning of civilization. ${ }^{2}$ For many years, Malta, like many other countries, used herbal medicine as the only form of medication making herbalism an integral part of the way of life of the Maltese society at the time. ${ }^{3}$

Herbal medicine at its origin was a phenomenon of both developed and undeveloped countries. ${ }^{4}$ With the arrival of modern synthetic drugs, about 100 years ago, medical herbalism was rendered almost extinct in countries like UK and USA. In other countries like India, China, and Germany, medical herbalism continued to play a role but did not remain the focus of every day used medications. ${ }^{5}$ Medical herbalism is coming back into focus once

\footnotetext{
* Corresponding author.

E-mail address: mspi0021@um.edu.mt (M. Spiteri).
}

again, and at present, $80 \%$ of the world populations use complementary medicine for primary healthcare. ${ }^{6,7}$

Currently, HMPs in Malta are mainly sold from pharmacies. Due to augmenting demands for HMPs by Maltese consumers, more pharmacists are stocking natural health products in their pharmacies. However, together with an increase in sales of HMPs, there is an increase in the number of consumers' inquiries with such consumers looking to pharmacists for evidence-based information. ${ }^{8-13}$ A significant intervention of a pharmacist today is to provide pharmaceutical advice, ${ }^{14}$ but many pharmacists appear to have little knowledge on natural health products, making them illequipped to implement this key recommendation.

Formularies are an effective way to improve prescribing practice, ${ }^{14}$ and the concept of formularies forms a basis of modern management systems. ${ }^{15}$ There are virtually no sources of referenced information regarding herbal therapy that are specific to products available in local community pharmacies. The study aimed at developing and evaluating a formulary of herbal medicinal products available in local pharmacies. 


\section{Materials and methods}

This study, leading to the compilation of a local herbal medicine formulary, assembled alphabetically according to the common names of the herbal substances, consisted of three main phases: (i) compilation of monographs for herbs and their validation, (ii) organization of relevant indices and printing of a complete formulary, and (iii) distribution of the formulary to all local pharmacies and evaluation of its usefulness.

\subsection{Data collection}

The preliminary phase was to obtain an exhaustive list of HMPs available on the local market. Four pharmacies were visited to study the different brands available locally. Local distributors were then contacted so as to develop a complete list of products for every brand. The products' list was narrowed down to HMPs, borderline substances, and food supplements, all of which contain herbal ingredients.

A thorough literature search for the active ingredients of each product was then carried out, either through the products' electronic site of the brand or by visiting pharmacies and reading on the package or package insert, such that another list was compiled. After having finalized a list of: (i) all the herbal products available on the local market and (ii) all the herbal ingredients present in the products mentioned above, various literature sources namely books, peer-reviewed articles in journals, and reliable internet sites were referred to, so as to initialize the compilation of the monographs on every herbal ingredient.

\subsection{Formulary compilation}

Monographs for all herbal substances were formulated. Every herbal monograph has stated the herbal common name (the title of the monograph), Latin binomial and the family and medicinal part(s) of the herb in question. Information on the indications (subdivided into principal, major, minor, and others were appropriate), cautions, contraindications, side-effects, drug interactions, and dosage follows. Each monograph ends with products containing that particular herb. Product information includes the trade name, brand, dosage form(s), active ingredient(s), and the name of the local distributor. Full product information is listed only once under the herb present in the highest dose within the product. The trade name and brand are then listed again under every herb present as part of the active ingredients and the reader is referred to the monograph under which the full product information is located.

The compiled monographs were handed over to 18 healthcare professionals (HCPs) of which 13 were pharmacists and five general practitioners (GPs), all of which have good knowledge or specialization in the field of herbal medicine, so as to validate monographs' information, giving particular attention to the indications. This validation exercise was essential since there is no published work stating clearly which indications are the principle, major, or minor. Twenty-nine laymen were also interviewed separately in pharmacies and health food shops and were asked for which indications they use the product(s) they would have just bought. This validation phase of the study was set up to verify the accuracy of the subdivisions of the indications and also to verify the effectiveness of the formulary.

Meanwhile, a total of four indices were collated: Herb name, product name, indications, and contraindications indices. The latter two were constructed by first inputting all the data in Microsoft Office Excel 2007 and then transferring the data into Microsoft Office Access 2007 to create queries and generate reports accordingly.
A complete formulary containing all the herbal substances and HMPs available locally was printed and disseminated in all, 216, local pharmacies. A questionnaire was distributed to 55 pharmacists and $10 \mathrm{GPs}$, irrespective of their knowledge on herbal medicine. Stratified sampling was adopted by subdividing the country into six districts. Its aim was to study the usefulness of the formulary amongst Maltese HCPs.

Microsoft Office Excel was used for the statistical analysis. All numerical determinations were analyzed using descriptive statistical tools with frequencies. Results were expressed as means, and only $P<0.05$ was considered significant.

\section{Results}

A total of 177 herbal monographs have been compiled and 612 herbal products listed. Out of the total number of products listed, 273 are present as a combination of herbal ingredients and 339 contain only one herbal substance.

Korean ginseng is the herb having the largest number of products listed within its monograph: 38 products are imported locally, whether in combination or containing Korean ginseng as the sole ingredient $(P<0.05, n=1194$ entries). This is followed by ginkgo, green tea, aloe, and echinacea with $36,35,33$, and 27 products each, respectively. Only $16 \%$ of the herbs $(n=153)$ feature in monocomponent products.

The most common indication that is referred to by the majority of the herbal substances is bronchitis. It is found mentioned in the indications of 41 species. This is followed by rheumatism, asthma, diarrhea, loss of appetite, and hemorrhoids which are present in 28, $26,24,23$, and 22 species, respectively. The majority of the indications, 587 out of a total of 812 distinctive indications, are only stated in the monograph of one species.

From all the herbal substances listed in the formulary, olive is the herb having the greatest number of indications, with 25 different indications appropriate for its usage $(P<0.05, n=177)$. This is followed by garlic with 23 indications and starflower, marigold and bilberry each having 21 indications. Six species: Tragacanth, senna, gamboge, yohimbe, kidney bean, and sorrel, have two indications each listed in their monograph. Only one herb, Hoodia, is used for a single indication, this being appetite suppression.

The commonest contraindication is pregnancy, stated for 79 species. Breast-feeding and stomach ulcers follow, being contraindicated in 29 and 11 species, respectively. The absolute majority of the contraindications, 92 out of a total of 134 distinct contraindications, are each mentioned in only one species.

A total of $30 \mathrm{HCPs}$ participated in the questionnaire, of which 22 were pharmacists and eight GPs, with a mean age of 36 years and with the majority of the participants being females (19). All participants found the formulary useful with 19 claiming to use it frequently and seven quite frequently [Fig. 1]. All the participants, except one, strongly agree with the fact that the formulary helped

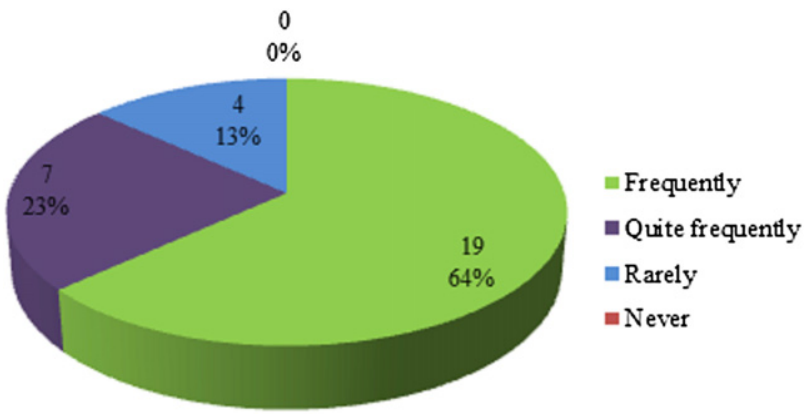

Fig. 1. How often the formulary was used per week $(n=30)$. 


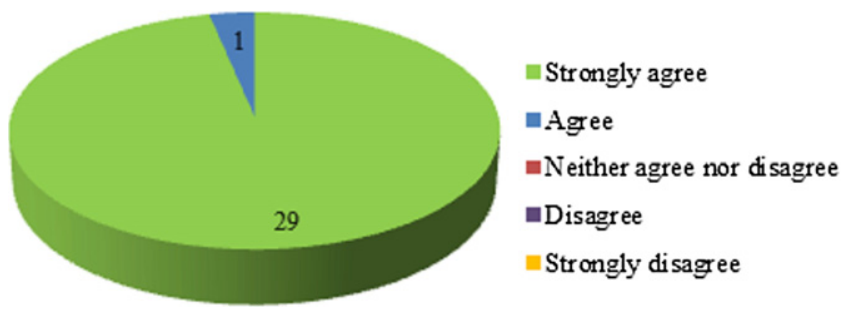

Fig. 2. Formulary helped in gaining knowledge on the locally available products $(n=30)$.

them learn which HMPs are present in the local market [Fig. 2], and 26 strongly agree that the information contained within the formulary was found to be useful [Fig. 3].

Participants $(n=30)$ agree that they have learned about individual herbs (26), the formulary is user-friendly (27), information included is up-to-date and well referenced (29) and that there is the need for a formulary of this kind in Malta (28). All participants agreed with subdividing the indications, and five commented on finding these subdivisions very useful and helpful when choosing which herbal substances to dispense for particular conditions.

\section{Discussion}

This study aimed to compile a formulary system that will ultimately help HCPs have a clear view of the herbal substances that are available for treating patients. All the participants that took part in the questionnaire found the formulary useful and helpful. The usefulness of the formulary is also evident from the high frequency of usage. Only four of the participants used the formulary rarely, possibly due to lack of patients making use of herbal products in specific areas. Frequency of usage varies between pharmacists and GPs but has no correlation with the age of participants. The four participants who rarely used the formulary were all GPs. A good number of herbal products are bought over-the-counter, and patients prefer to go directly to the pharmacist rather than visiting a doctor when they prefer to have an herbal medication.

Korean ginseng is the most popular herb amongst the Maltese community since it is the herb having the greatest number of products imported locally. Ginseng ranks 26th on the traditional use registration (TUR) list provided by the European Medicines Agency. ${ }^{16}$ The TUR, amongst other parameters, indicates the quantity of medicinal products used in the EU. This low ranking may be attributed to the fact that most ginseng products are food supplements rather than herbal medicines. Ginkgo and green tea are the two other leading popular herbs in Malta. These three herbs have a common use, namely cardiovascular diseases. Coronary artery disease and stroke are the leading causes of death in both men and women and are also important causes of morbidity in Malta. ${ }^{17}$ This points to a possible explanation to why Korean ginseng, ginkgo, and green tea are the most popular herbs locally.

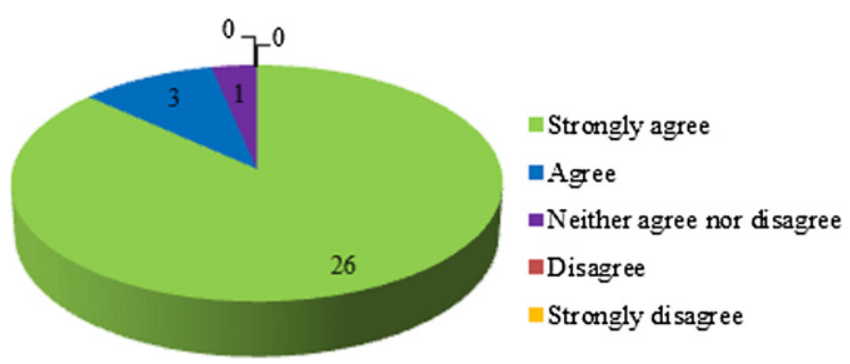

Fig. 3. Usefulness of information contained within the formulary $(n=30)$.
Amongst the six most mentioned indications in the formulary's monographs, bronchitis and asthma are related conditions. Cough is another symptom related to the latter two conditions, ranking as the 10th most mentioned indication. Eight herbal substances (dquai, brahmi, wood betony, sundew, ephedra, grindelia, hyssop, and mullein) can be used for asthma and bronchitis; three (grindelia, hyssop, wood betony) can be used for all the three conditions. Grindelia and hyssop are specific for treating such conditions since these indications are listed as 'principal' or 'major'; wood betony lists them under 'others' indications. The European Medicines Agency reports that $17 \%$ of the TUR products $(n=785)$ and $25 \%$ of the well-established use (WEU) products are registered or authorized for use in cough and cold conditions. ${ }^{18}$

Different herbal substances vary in the number of indications they can treat or prevent. Herbal substances having an extensive list of indications are very often non-specific in treating particular conditions. This justifies the need to classify such indications as 'principal,' 'major,' 'minor,' and 'others'. Herbs having few indications are often more specific. Tragacanth, senna, and gamboge all have only two indications each. They are all primarily used for constipation, showing specificity in treating such a condition.

Aloe vera has been debated for its status, as whether it is a HMP or a food supplement. Today, there is a clearer distinction between aloe products as the presence of anthraquinone glycosides distinguishes whether the product is a medicine or not. Yohimbe and cascara are both considered as HMPs. Therefore, the fact that these products should be used with care, due to their indications and contraindications, they qualify as HMPs rather than food supplements. ${ }^{19}$

The fact that several herbal products are contraindicated in pregnancy may be due to the very few studies reporting the effects of herbs in pregnancy and in most cases, the statement 'the use of this herb in pregnancy has not been reported' is common to many products found in the formulary. The same is observed with breastfeeding though this is given less importance than pregnancy. As regards to stomach ulceration, especially for orally administered herbal products, the first site of contact is the stomach. ${ }^{20}$ Therefore, the effect would be a possible immediate observation when compared to effects on other organs.

The presentation of the formulary was greatly accepted by all participants, making it more probable for HCPs to use it. In fact, 19 (63\%) participants said that they used the formulary frequently and seven (23\%) quite frequently.

The classification of herbal medicinal products ${ }^{21}$ and subsequently sub-classes, traditional HMPs, and herbals with a wellestablished use, ${ }^{22}$ has been a priority to the European Medicines Agency. The agency, a body of the European Union, has published several herbal monographs, through its Committee on Herbal Medicinal Products (HMPC), in order to clarify the status of certain herbal products for the European market. ${ }^{23}$

The transposition of the Herbals Directive (2004/24/EC) ${ }^{24}$ and its subsequent amendments in all member states is a lengthy process. Within this transition, the formulary will assist local authorities and HCPs on the presence of herbal products available on the Maltese market.

\section{Conclusion}

The formulary was found to be a very useful tool that supports pharmacists and GPs in evidence-based prescribing and recommendation of herbal products. The formulary is an accepted tool by the local HCPs, and its aim to inform and support the healthcare decision-making process has been reached. HCPs are provided with knowledge on a limited range of natural medications, resulting in enhanced monitoring of drug therapy and improved patient care. 
The formulary was developed in such a way as to be informative but at the same time easy to follow, user-friendly, and attractive. Since the available products are changing continuously, with some being newly introduced and a lot others being discontinued, there is the need for frequent updates. Formularies require constant evaluation and should be updated regularly so as to remain an efficient tool for modern management systems. With the increase in IT equipment, including tablets and smartphones, the launching of the formulary in an electronic format may be a possibility. This will facilitate updates and improvements in the final product when needed.

\section{Conflicts of interest}

All authors have none to declare.

\section{References}

1. Atmakuri LR, Dathi S. Current trends in herbal medicines. J Pharm Res. 2010;3: 109-113.

2. Chong's Health Care Enterprise, Inc. History of Herbal Medicine, Alternative Medicine, Medicinal Herbs [Online] [Last cited on 2011 Feb 03]. Available from: http://www.herbpalace.com/alternative-medicine/herbal-medicine.html; 2003 Accessed 15.01.13.

3. Zammit Montebello M. Herbal Remedies [Project]. Msida (Malta): Department of Pharmacy, University of Malta; 1988.

4. Gossell-Williams M, West ME. The past and present use of plants for medicines. West Indian Med J. 2006;55(4):217-218.

5. Ernst E. Herbal Medicine - A Concise Overview for Professionals. Oxford: Butterworth-Heinemann; 2000.

6. Iqbal Choudhary M, Mosihuzzaman M. Protocols on safety, efficacy, standardization and documentation of herbal medicine. Pure Appl Chem. 2008;80:2195-2230.

7. Aneesh TP, Revikumar KG, Sekhar MS, Varghese KJ, Vasudaven DT. Herbalism: a phenomenon of new age in medicine. Int J Pharm. 2008;6:8.

8. Austin Z, Boon H, Eccott L, et al. Canadian pharmacy students' knowledge of herbal medicine. Am J Pharm Educ. 2008;72:75.

9. Bryant PJ, Clauson KA, McQueen CE, Shields KM. Knowledge and attitudes of pharmacists in Missouri regarding natural products. Am JPharm Educ. 2003;67:41.
10. Chang ZG, Holdford DA, Kennedy DT, Small RE. Pharmacists' knowledge and attitudes toward herbal medicine. Ann Pharmacother. 2000;34:710-715.

11. Dolder C, Dolder N, Gregory P, Lacro J. Pharmacists' use of and attitudes and beliefs about alternative medicine. Am J Health Syst Pharm. 2003;60:1352-1357.

12. Hadsall RS, Schommer JC, Welna EM. Pharmacists' personal use, professional practice behaviours, and perceptions regarding herbal and other natural products. J Am Pharm Assoc. 2001;43:602-611.

13. Cauffield JS, Chin TW, Harris IM, et al. White paper on herbal products. Pharmacotherapy. 2000;20:877-891.

14. Bissell P, Blenklnsopp A, Mason L, Short D. Patients' experiences of a community pharmacy-led medicines management service. Health Soc Care Comm. 2008; 16:363-369.

15. Khan F. Using medicines wisely - the place of the formulary in medicines management. Hosp Pharm. 2002;9:159-163.

16. European Medicines Agency. Uptake of the Traditional use Registration Scheme and Implementation of the Provisions of Directive 2004/24/EC in EU Member States; 2011. EMA/322570/2011 Rev. 1.

17. Ministry for Health, the Elderly and Community Care. A Strategy for the Prevention and Control of Noncommunicable Diseases in Malta. Malta: Progress Press Company Ltd.; 2010.

18. Ling AM. FDA to ban sales of dietary supplements containing ephedra. J Law Med Ethics. 2004;32:184-186.

19. European Medicines Agency. Guideline on Declaration of Herbal Substances and Herbal Preparations in Herbal Medicinal Products/Traditional Herbal Medicinal Products [Online] [Last cited on 2012 Jul 23]. Available from: http://www. ema.europa.eu/docs/en_GB/document_library/Scientific_guideline/2009/09/ WC500003272.pdf; 2010 Accessed 15.01.13.

20. Coboeken K, Dressman JB, Lippert J, Thelen K, Willmann S. Evolution of a detailed physiological model to stimulate the gastrointestinal transit and absorption process in humans, part II: extension to describe performance of solid dosage forms. J Pharm Sci. 2012;101:1267-1280.

21. Attard E. Herbal medicine: a legal persective. Synapse. 2011;1:11.

22. Attard E. Herbal medicinal products - the two sides of the coin. Synapse. 2011;2:15.

23. European Medicines Agency. Human Medicines - Herbal Medicinal Products [Online] [Last cited on 2012 Jul 23]. Available from: http://www.ema.europa.eu/ ema/index.jsp?curl=pages/regulation/general/general_content_000208.jspand mid=WC0b01ac05800240cf; 2012 Accessed 15.01.13.

24. Directive 2004/24/EC of the European Parliament and of the Council of 31 March 2004 amending, as regards traditional herbal medicinal products, Directive 2001/83/EC on the community code relating to medicinal products for human use. Official Journal of the European Union. 2004;136:85-90. 